\title{
Effects of sand-fixing and windbreak forests on wind flow: a synthesis of results from field experiments and numerical simulations
}

\author{
ZHAN Kejie ${ }^{1,2}$, LIU Shizeng ${ }^{2}$, YANG Zihui ${ }^{2}$, FANG Etian², ZHOU Lanping ${ }^{2}$, HUANG \\ $\mathrm{Ning}^{1 *}$ \\ ${ }^{1}$ Key Laboratory of Mechanics on Western Disaster and Environment in China (Ministry of Education), Department of \\ Mechanics, Lanzhou University, Lanzhou 730000, China; \\ ${ }^{2}$ Minqin National Station for Desert Steppe Ecosystem Studies, Minqin 733000, China
}

\begin{abstract}
Sand-fixing and windbreak forests are widely used to protect or/and improve the ecological environments in arid and semi-arid regions. A full understanding of wind flow characteristics is essential to arranging the patterns of these protective forests for enhancing the effectiveness. In this study, the wind velocity over the underlying surface with sand-fixing forests and windbreak forests at the heights of 1-49 $\mathrm{m}$ was monitored from two 50-m high observation towers in an oasis of Minqin, Gansu Province of China. The wind velocities were simulated at different locations over these protective forests between those two towers by a two-dimensional Computational Fluid Dynamics (CFD) model. The results showed that at the heights of 1-49 $\mathrm{m}$, the wind velocity profiles followed a classical logarithm law at the edge of the oasis and a multilayer structure inside the oasis. With increasing number of sand-fixing forest and windbreak forest arrays, the wind velocity at the heights of 1-49 $\mathrm{m}$ generally decreased along the downstream direction of the prevailing wind. Specifically, below the height of windbreak forests, the wind velocity decelerates as the airflow approaches to the windbreak forests and then accelerates as the airflow passes over the windbreak forests. In contrast, above the height of windbreak forests, the wind velocity accelerates as the airflow approaches to the windbreak forests and then generally decelerates as the airflow passes over the windbreak forests. Both the array number and array spacing of sand-fixing and windbreak forests could influence the wind velocity. The wind protection effects of sand-fixing forests were closely related to the array spacing of windbreak forests and increased with the addition of sand-fixing forests when the array of the forests was adequately spaced. However, if the array spacing of windbreak forests was smaller than seven times of the heights of windbreak forests, the effects were reduced or completely masked by the effects of windbreak forests. The results could offer theoretical guidelines on how to systematically arrange the patterns of sand-fixing and windbreak forests for preventing wind erosion in the most convenient and the cheapest ways.
\end{abstract}

Keywords: wind velocity; sand-fixing forest; windbreak forest; computational simulation; Minqin

Citation: ZHAN Kejie, LIU Shizeng, YANG Zihui, FANG Etian, ZHOU Lanping, HUANG Ning. 2017. Effects of sand-fixing and windbreak forests on wind flow: a synthesis of results from field experiments and numerical simulations. Journal of Arid Land, 9(1): 1-12. doi: 10.1007/s40333-016-0058-z

\footnotetext{
*Corresponding author: HUANG Ning (E-mail: huangn@1zu.edu.cn)

Received 2015-12-01; revised 2016-05-03; accepted 2016-06-15

(C) Xinjiang Institute of Ecology and Geography, Chinese Academy of Sciences, Science Press and Springer-Verlag Berlin Heidelberg 2017
} 


\section{Introduction}

Sand-fixing and windbreak forests in the form of networks and fences were widely used to improve the local ecological environments in arid and semi-arid regions, and the improvement was accomplished through altering airflow patterns to prevent wind erosion and control heat and moisture transfers (Wilson, 1985; Cleugh, 1998; Cleugh and Hughes, 2002; Brandle et al., 2004; Huang et al., 2005; Li et al., 2007). Sand-fixing and windbreak forests are the main components of the Three-North Shelterbelt Project, known as the "Green Great Wall" of China (Wang and Zhou, 2003).

A full understanding of the wind flow characteristics is essential to arranging the patterns of sand-fixing and windbreak forests. The effects and aerodynamics of sand-fixing and windbreak forests or artificial fences have been persistently investigated through field observations (see Schwartz et al., 1995; Mohammed et al., 1996; Wilson, 2004; Tuzet and Wilson, 2007; Amichev et al., 2015; Li et al., 2016), wind tunnel experiments (see Schwartz et al., 1995; Judd et al., 1996; Lee et al., 2002) and theoretical analyses (see Zhu and Zhou, 1993; Cleugh, 1998; Takahashi et al., 1998; Ucar and Hall, 2001; Amichev et al., 2015). It should be stressed that field observation has been the most frequently used method because of its readiness. But, most previous field observations on windbreak forests were limited to the range of 0-10 m height (Guo et al., 2014). However, the windbreak forests are usually higher than $10 \mathrm{~m}$. Therefore, those previous observations failed to take account of the aerodynamics above $10 \mathrm{~m}$ in height. Needless to say, wind tunnel experiments often failed to capture the reality mostly due to the limitation of wind tunnel size (Santiago et al., 2007). This study extended the observation height to $49 \mathrm{~m}$ with a hope to more reliably describe the wind flow characteristics of sand-fixing and windbreak forests.

Computer simulation methods have been used in numerous fields related to fluid dynamics as they can efficiently and accurately compute and predict the behavior of airflow (Beaucage et al., 2014). Several studies were carried out to simulate the aerodynamics of wind either flowing through shelterbelts or flowing through porous media (e.g. Wang and Takle, 1995; Cleugh, 1998; Patton et al., 1998; Lee and Lim, 2001; Sanz, 2003; Katul et al., 2004; Li et al., 2006; Hoffman et al., 2015). However, these simulations were mainly concentrated on the influence of the shelterbelt porosity and the effect of single or double arrays of shelterbelts. In reality, a forest protection system is usually composed of more than double arrays of forests with different spacing distances. Those simulation studies thus failed to provide useful references for evaluating the protective effects of multiple-array sand-fixing and windbreak forests.

In this study, we monitored the wind velocity of gale events over the underlying surface with sand-fixing and windbreak forests at the heights of 1-49 $\mathrm{m}$ using two 50-m high observation towers, one inside and another at the edge of an oasis of Minqin, Gansu Province, China. As Computational Fluid Dynamics (CFD) is a branch of fluid mechanics that solves and analyzes problems involving a fluid flow by means of computer-based simulations and enables the evaluation of specific parameters (Lecrivain et al., 2008), we developed a two-dimensional CFD model to simulate the wind velocity within the height of $50 \mathrm{~m}$ at different locations to evaluate the influences of sand-fixing and windbreak forests on wind flow. At the same time, the wind velocities with the sand-fixing forests and without the sand-fixing forests accompanying the windbreak forests were compared to further assess the effects of sand-fixing forests on wind velocity. The objective of this study is to quantitatively assess the influences of sand-fixing and windbreak forests on wind flow.

\section{Study area and methods}

\subsection{Study area}

The field experiment was conducted in an oasis of Minqin County, Gansu Province, China $\left(38^{\circ} 34^{\prime} 28^{\prime \prime} \mathrm{N}, 102^{\circ} 59^{\prime} 05^{\prime \prime} \mathrm{E}\right.$; Fig. 1). The area is situated in the lower reaches of the Shiyang River Basin. Mean annual precipitation is $116.36 \mathrm{~mm}$ and mean annual evaporation is $2383.7 \mathrm{~mm}$. The prevailing wind comes from northwest and the mean occurrence of gale-force events (velocity $\geq 17$ 
$\mathrm{m} / \mathrm{s}$ ) is $27.4 \mathrm{~d} / \mathrm{a}$ with an annual mean wind velocity of $2.4 \mathrm{~m} / \mathrm{s}$ and an annual mean sandstorm occurrence of $25 \mathrm{~d} / \mathrm{a}$.

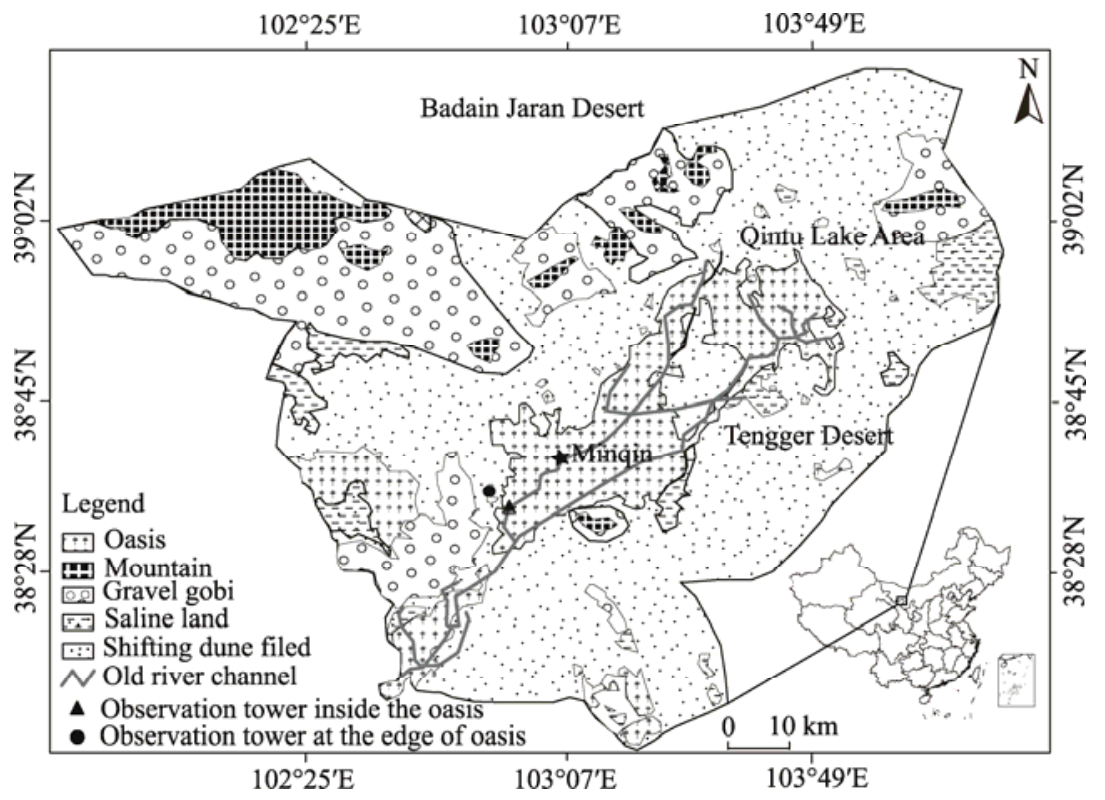

Fig. 1 Location of the study area in Minqin County, Gansu Province, China

\subsection{Data collection and analysis}

We monitored the wind velocity of gale events from February to April 2006 at the heights of 1-49 $\mathrm{m}$ from two 50-m high observation towers constructed by the Gansu Desert Control Research Institute. One of the two observation towers is located at the edge of the Minqin Oasis and the other inside the oasis. The tower at the edge of the oasis is situated directly at the upstream of the tower inside the oasis with reference to the prevailing wind direction (northwest). The distance between the two towers is $3.5 \mathrm{~km}$ and multiple arrays of sand-fixing and windbreak forests are distributed between these two towers. The sand-fixing forests mainly consist of Haloxylon ammodendron, with a mean height of $1.6 \mathrm{~m}$, a mean crown dimension of $0.89 \mathrm{~m}$, a mean density of 570 trees $/ \mathrm{hm}^{2}$ and a mean array spacing of $9 \mathrm{~m}$. The windbreak forests mainly consist of Poplar sp., with a mean height of $18 \mathrm{~m}$, a mean crown dimension of $3.5 \mathrm{~m}$, varying density and varying array spacing. Wind velocity was observed at 13 different heights $(1,5,9,13,17,21,25$, 29, 33, 37, 41, 45 and $49 \mathrm{~m}$ ) by three-cup anemometers (DES1, Changchun, China) at each of these two towers. When the prevailing wind from the northwest reached a certain velocity (e.g., $\sim 5 \mathrm{~m} / \mathrm{s}$ at the height of $1 \mathrm{~m}$ ), the mean wind velocity at different heights was recorded at an interval of 5 min by a data logger. All the data were analyzed using OriginPro 7.5 (OriginLab Corp, Northampton, MA, USA).

\subsection{Numerical simulation}

In this study, the FLUENT software was used, along with the gird-generating GAMBIT 2.2 software for pre-modeling configuration.

\subsubsection{Basic assumptions}

The following assumptions were made: incompressible flow, steady state, flat terrain, and homogeneous sand-fixing and windbreak forests.

\subsubsection{Model selection and governing equations}

There are many turbulence models to describe airflow patterns in the atmospheric boundary layer. Among these, the $k-\varepsilon$ model has a proven ability to simulate airflow patterns above a forest (Kobayashi et al., 1994; Liu et al., 1996; Sanz, 2003; Katul et al., 2004; Alinot and Masson, 2005, Li et al., 2006; Blocken et al., 2007; Dalpé and Masson, 2009). FLUENT software, the adopted 
software for this study, provides three kinds of $k-\varepsilon$ models: standard, renormalization-group (RNG), and realizable $k-\varepsilon$ models. Santiago et al. (2007) assessed the performance of these three turbulence models using wind tunnel experiments and found that the RNG and realizable $k-\varepsilon$ models seemed to perform better than the standard $k-\varepsilon$ model. In this study, we selected the RNG $k-\varepsilon$ model to carry out the numerical simulations.

The simulations were based on Reynolds-averaged Navier-Stokes (RANS) equations. Four types of equations were solved: continuity Equation 1, RANS Equation 2, and two turbulence closure equations for turbulent kinetic energy $(k)$, Equation 3 and the dissipation rate of turbulent kinetic energy $(\varepsilon)$, Equation 4. Besides, the Reynolds stress was calculated by Equation 5.

$$
\begin{gathered}
\frac{\partial u_{j}}{\partial x_{j}}=0 \\
\frac{\partial u_{i}}{\partial t}+u_{j} \frac{\partial u_{i}}{\partial x_{j}}=\frac{\mu}{\rho} \frac{\partial^{2} u_{i}}{\partial x_{j} \partial x_{j}}-\frac{1}{\rho} \frac{\partial p}{\partial x_{i}}-\frac{\partial}{\partial x_{j}}\left(\overline{u_{i}^{\prime} u_{j}^{\prime}}\right)+g_{i} . \\
\frac{\partial k}{\partial t}+u_{j} \frac{\partial k}{\partial x_{j}}=\frac{1}{\rho} \frac{\partial}{\partial x_{j}}\left(\alpha_{k} \mu_{e f f} \frac{\partial k}{\partial x_{j}}\right)+\frac{G_{k}}{\rho}-\varepsilon . \\
\frac{\partial \varepsilon}{\partial t}+u_{j} \frac{\partial \varepsilon}{\partial x_{j}}=\frac{1}{\rho} \frac{\partial}{\partial x_{j}}\left(\alpha_{\varepsilon} \mu_{e f f} \frac{\partial \varepsilon}{\partial x_{j}}\right)+\frac{1}{\rho} C_{\varepsilon 1} G_{k} \frac{\varepsilon}{k}-\left(C_{\varepsilon 2}+\frac{C_{\mu} \rho \eta^{3}\left(1-\eta / \eta_{0}\right.}{1+\beta \eta^{3}}\right) \frac{\varepsilon^{2}}{k} . \\
\frac{u_{i}^{\prime} u_{j}^{\prime}}{k}=-\frac{1}{\rho} \mu_{t}\left(\frac{\partial u_{i}}{\partial x_{j}}+\frac{\partial u_{j}}{\partial x_{i}}\right)+\frac{2}{3} k \delta_{i j} .
\end{gathered}
$$

Where, $u_{j}$ is the $j$ component of velocity $(\mathrm{m} / \mathrm{s}), x_{j}$ the $j$ coordinate; $u_{i}(\mathrm{~m} / \mathrm{s})$ is the $i$ component of velocity, $t$ (s) the time, $x_{i}$ the $i$ coordinate, $\rho\left(\mathrm{kg} / \mathrm{m}^{3}\right)$ the density of the air, $\mu\left(\mathrm{m}^{2} / \mathrm{s}\right)$ the dynamic viscosity, $\overline{u_{i}^{\prime} u_{j}^{\prime}}$ the Reynolds stress, $g_{i}\left(\mathrm{~m} / \mathrm{s}^{2}\right)$ the gravitational body force; $\mu_{\text {eff }}$ is the effective turbulent viscosity, $G_{k}$ represents the turbulence kinetic energy resulted from the mean velocity gradients, $\alpha_{k}$ and $\alpha_{\varepsilon}$ are the inverse effective Prandtl number for $k$ and $\varepsilon$, respectively, $\eta$ is the ratio of $S k$ to $\varepsilon$ (note: $S$ is the scalar measure of deformation tensor), $\delta_{i j}$ the Kronecker symbol. The default values of the model constants $\eta_{0}, \beta, C_{\varepsilon 1}, C_{\varepsilon 2}$, and $C_{\mu}$ are listed in Table 1 (Shih et al., 1995; Fluent, 1996; Chan et al., 2002; Santiago et al., 2007).

Table 1 Default values for the constants of the $k$ - $\varepsilon$ turbulence model

\begin{tabular}{cccccc}
\hline Parameter & $\eta_{0}$ & $\beta$ & $C_{\varepsilon 1}$ & $C_{\varepsilon 2}$ & $C_{\mu}$ \\
\hline Value & 4.38 & 0.012 & 1.42 & 1.68 & 0.0845 \\
\hline
\end{tabular}

2.3.3 Modeling sand-fixing and windbreak forests and their interaction with wind

The CFD model is two-dimensional one: 4300-m long and 200-m high. It consists of multiple arrays of sand-fixing forests (a mean height of $1.6 \mathrm{~m}$ and an equally-distanced array spacing of 9 $\mathrm{m}$ ) and 12 arrays of windbreak forests (a mean height of $18 \mathrm{~m}$ and a varying array spacing of $72-410 \mathrm{~m}$ ), being similar to the field reality (Fig. 2).

2.3.4 Domain and grid

In this study, a two-dimensional grid was generated using the grid generator GAMBIT. Taking into account of the computer capacity and also the expectation for the result accuracy, we set the distance between the horizontal and vertical grid points around the sand-fixing and windbreak forests at less than $0.4 \mathrm{~m}$. The grid space increased with height up to $3 \mathrm{~m}$ (the top of the calculation domain). A total of 13 study locations (A-M) were chosen in this study (Fig. 2).

2.3.5 Boundary conditions

At the inlet boundary, the inflow velocity profile along a direction perpendicular to the flat surface obtained from the tower at the edge of the oasis followed a logarithmic equation (Eq. 6) 


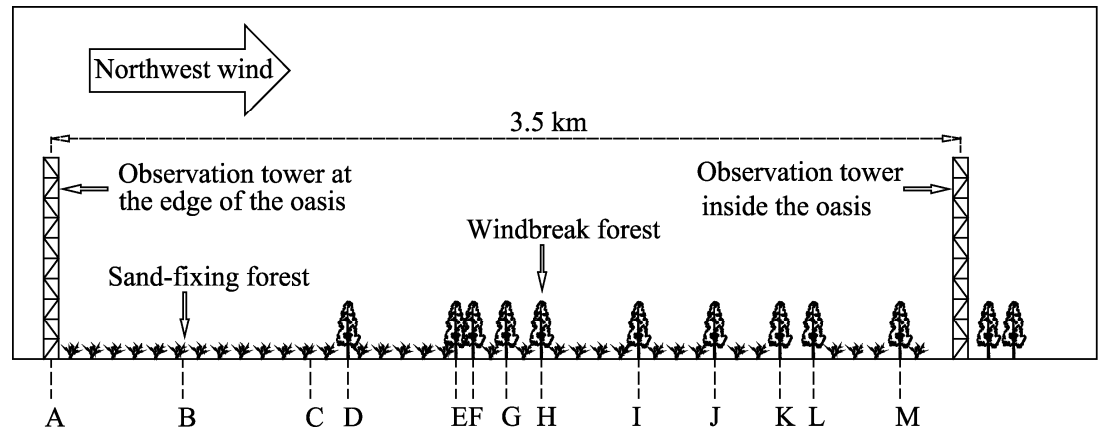

Fig. 2 Sketch map of the computational domain and the study locations (A-M). Note 1: the horizontal scale was greatly compressed in comparison with the vertical scale. Note 2: the distances both between the locations A and $\mathrm{B}$ and between the locations $\mathrm{B}$ and $\mathrm{C}$ within the sand-fixing forest were $500 \mathrm{~m}$. Note 3: the distances between two neighboring study locations within the windbreak forests are varying, ranging from 72 to $410 \mathrm{~m}$.

defined by the UDF function in FLUENT software. The turbulent kinetic energy of velocity inlet boundary $\left(k_{i n}\right)$ and the dissipation rate of turbulent kinetic energy of velocity inlet boundary $\left(\varepsilon_{i n}\right)$ were obtained by Equations 7 and 8, respectively (Fluent, 1996).

$$
\begin{gathered}
u_{(z)}=\left(\frac{u_{*}}{K}\right) \ln \left(\frac{z}{z_{0}}\right) . \\
k_{\text {in }}=\frac{3}{2}\left(u_{\mathrm{avg}} I\right)^{2} . \\
\varepsilon_{\text {in }}=C_{\mu}^{3 / 4} \frac{k^{3 / 2}}{l} .
\end{gathered}
$$

Where, $u_{(z)}(\mathrm{m} / \mathrm{s})$ is the mean wind velocity at height $z(\mathrm{~m}), u_{*}(\mathrm{~m} / \mathrm{s})$ the friction velocity, and $z_{0}(\mathrm{~m})$ the aerodynamic roughness length, $u_{*}$ and $z_{0}$ were calculated from the velocity profile obtained from the tower at the edge of the oasis, $K$ is the Karman's constant, being equal to $0.4 ; u_{\mathrm{avg}}(\mathrm{m} / \mathrm{s})$ is the mean flow velocity, $I(\%)$ the turbulence intensity that was calculated from the field experiment data; $C_{\mu}$ is an empirical constant specified in the turbulence model (approximately $0.09)$, and $l(\mathrm{~m})$ is the turbulence length scale.

At the outlet boundary, the flow was assumed to be a fully developed flow. Because the top boundary was sufficiently high above the ground surface, symmetrical boundary conditions were applied. At the ground boundary, a no-slip condition was used. Each array of sand-fixing forests or windbreak forests was simplified as an idealized porous media. The physical effect of the presence of a porous medium on the flow was equivalent to a pressure drop through it, creating a momentum sink. The pressure change $(\Delta p)$ was defined as a combination of Darcy's Law and an additional inertial loss term, which could be expressed as Equation 9 (Fluent, 1996).

$$
\Delta p=-\left(\frac{\mu}{\alpha} v+C_{2} \frac{1}{2} \rho v^{2}\right) \Delta m .
$$

Where, $\alpha\left(\mathrm{m}^{2}\right)$ is the permeability of the medium, $C_{2}(1 / \mathrm{m})$ the pressure-jump coefficient, $v(\mathrm{~m} / \mathrm{s})$ the velocity normal to the porous face, and $\Delta m(\mathrm{~m})$ the thickness of the medium.

\subsection{Derivation of friction velocity $\left(u_{*}\right)$ and aerodynamic roughness length $\left(z_{0}\right)$}

It general, the mean wind velocity in a neutral turbulent boundary layer with uniform air density and with a small temperature gradient follows the logarithmic equation (Eq. 6). However, over large rough surfaces such as trees or shrubs, it should be calculated by Equation 10 .

$$
u_{(z)}=\left(\frac{u_{*}}{K}\right) \ln \left(\frac{(z-d)}{z_{0}}\right) .
$$

Where, $u_{(z)}(\mathrm{m} / \mathrm{s})$ is the mean wind velocity at height $z(\mathrm{~m})$, and $d(\mathrm{~m})$ the zero-displacement height, being generally dependent on the height of trees or shrubs. 


\section{Results and discussion}

\subsection{Observed wind velocity}

At the edge of the oasis, the wind velocity of gale events at the heights of 1-49 $\mathrm{m}$ exhibited a logarithmically linear relationship with the height (Fig. 3a). We calculated $u_{*}$ and $z_{0}$ based on the observed wind velocities. The mean value of $u_{*}$ was $0.80 \mathrm{~m} / \mathrm{s}$ and the mean value of $z_{0}$ was 13.7 $\mathrm{mm}$. However, the wind velocity profiles of gale events at the heights of 1-49 m inside the oasis differed significantly from those at the edge of the oasis (Fig. 3b). To study the effects of sand-fixing and windbreak forests on wind flow characteristics, we divided the wind velocity profiles inside the oasis at the heights of 1-49 $\mathrm{m}$ into two portions based on the mean height of windbreak forests: upper portion above $18 \mathrm{~m}$ and lower portion below $18 \mathrm{~m}$. The upper portion profiles well fit the curves defined by Equation 10, in which $d$ was $9 \mathrm{~m}$ (half of the mean height of windbreak forests), mean $u_{*}$ was $1.16 \mathrm{~m} / \mathrm{s}$ and mean $z_{0}$ was $444 \mathrm{~mm}$. Our comparison shows that both $u_{*}$ and $z_{0}$ were higher in the upper portion inside the oasis than the counterparts at the edge of the oasis, manifesting the important influences of sand-fixing and windbreak forests on airflow in the upper portion. The lower portion profiles do not fit the curves defined either by Equation 6 or by Equation 10. Figure 3b shows that the wind velocity increases faster with increasing height in the lower portion than in the upper portion inside the oasis.
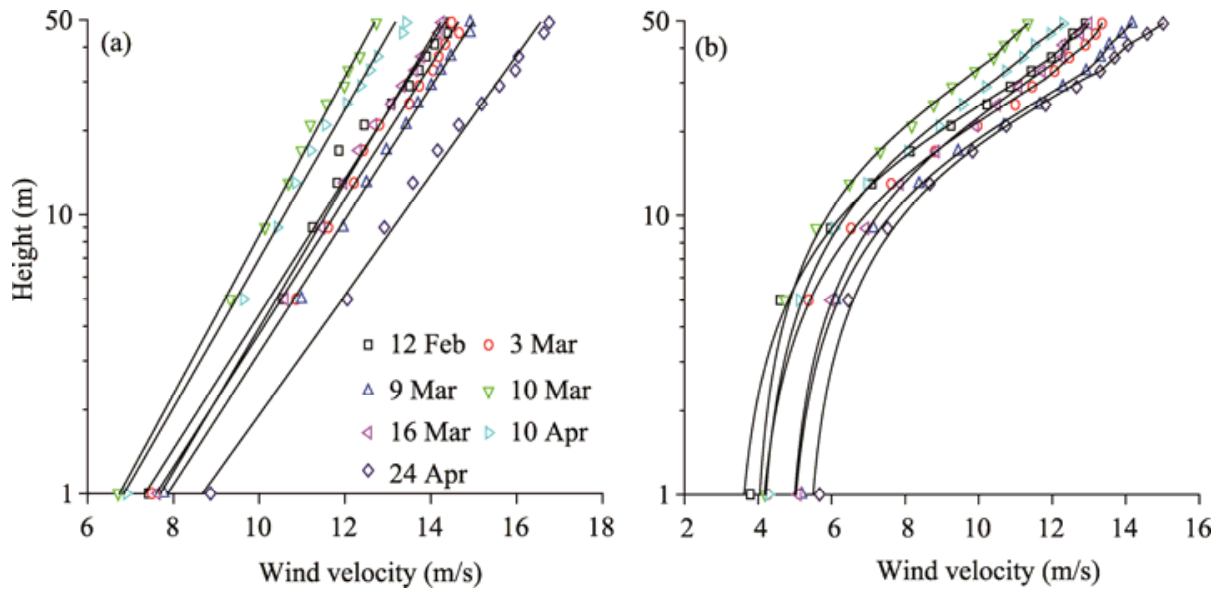

Fig. 3 Observed wind velocity of seven gale events in 2006 at the heights of 1-49 m at the edge of the oasis (a) and inside the oasis (b)

\subsection{Validation of numerical simulation results}

To validate the simulation results, we used the wind velocity profiles observed at the edge of the oasis during gale events as the inflow velocity profiles and we then simulated the wind velocity profiles for both inlet (i.e., the tower at the edge of the oasis) and outlet (i.e., the tower inside the oasis) using the CFD model. Our comparison between the observed data and the simulated results (Fig. 4) shows that the simulated results well match the observed data, boosting our confidence on using the CFD model to simulate the wind velocity profiles.

\subsection{Simulated wind velocity at different locations}

The simulated results of wind velocity profiles at different locations (i.e., locations A, B, C, ..., M in Figure 2) between the two observation towers are shown in Fig. 5. With increasing number of sand-fixing forest and windbreak forest arrays, the velocity generally decreased along the prevailing wind direction and the wind velocity profiles within the considered heights (i.e., 1-49 $\mathrm{m})$ varied significantly. Figure 5 also shows that the lower-standing sand-fixing forests (i.e., at locations $\mathrm{A}, \mathrm{B}$ and $\mathrm{C}$ in Figure 2) had considerably less effects than the higher-standing windbreak forests (i.e., at locations from D to $\mathrm{M}$ in Figure 2). Specifically, over the 1000-m horizontal distance from locations $\mathrm{A}$ to $\mathrm{C}$ where there existed many arrays of sand-fixing forests, 
the wind velocity seemed to be influenced by the sand-fixing forests only within the heights of 1-30 m. However, once the airflow passed through the third array of windbreak forests, the wind velocity was greatly reduced from the ground level (i.e., $1 \mathrm{~m}$ ) to the top of the considered layer (i.e., $49 \mathrm{~m}$ ) and the velocity reduction was most significant within the heights of $1-40 \mathrm{~m}$.

In addition, just as the aerodynamic roughness length $\left(z_{0}\right)$ is dependent on several characteristics of the surface features (e.g., height, shape, spacing, etc.) (Wolf and Nickling, 1993), the wind velocity is also dependent on several characteristics of the surface features and the surface features here refer to sand-fixing forests and windbreak forests. It means that the wind velocity does not necessarily always decrease with increasing arrays of sand-fixing and windbreak forests. For example, although the study locations E, F, G and H were situated at the upstream of the study location $\mathrm{J}$ along the prevailing wind, the wind velocities at these locations (i.e., E-H) within 1-20 m heights were lower than the velocity at location $\mathrm{J}$ because of the shorter array spacing (Fig. 6). It should also be noted that the aerodynamic roughness lengths $\left(z_{0}\right)$ of these locations (i.e., E-H) above $20 \mathrm{~m}$, calculated with Equation 6, was averagely $3381 \mathrm{~mm}$, being much higher than that of location $\mathrm{J}(1560 \mathrm{~mm})$.

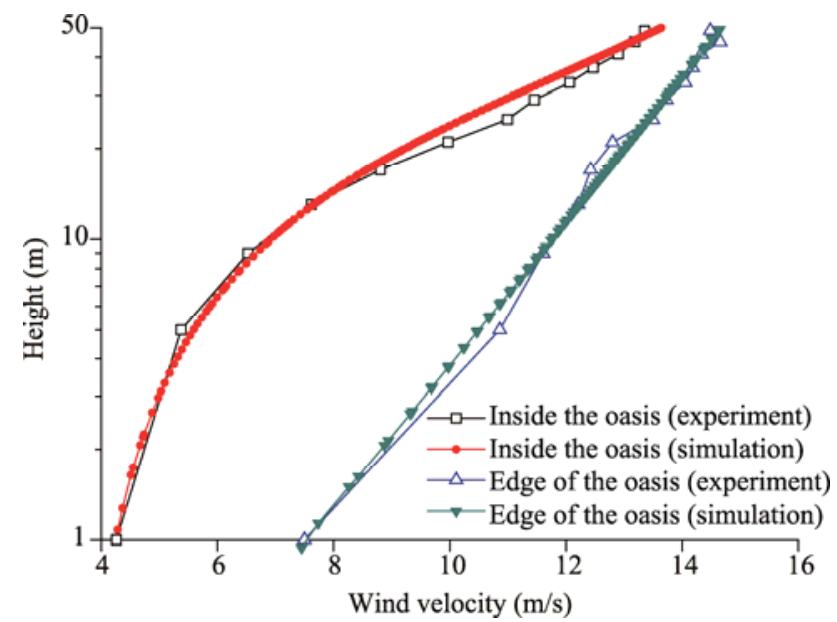

Fig. 4 Observed and simulated wind velocities at the heights of 1-49 $\mathrm{m}$ inside the oasis and at the edge of the oasis. The observed wind velocity data were obtained on 3 March 2006 from the two 50-m high observation towers: one inside the oasis and another at the edge of the oasis (tower locations in Fig. 1).

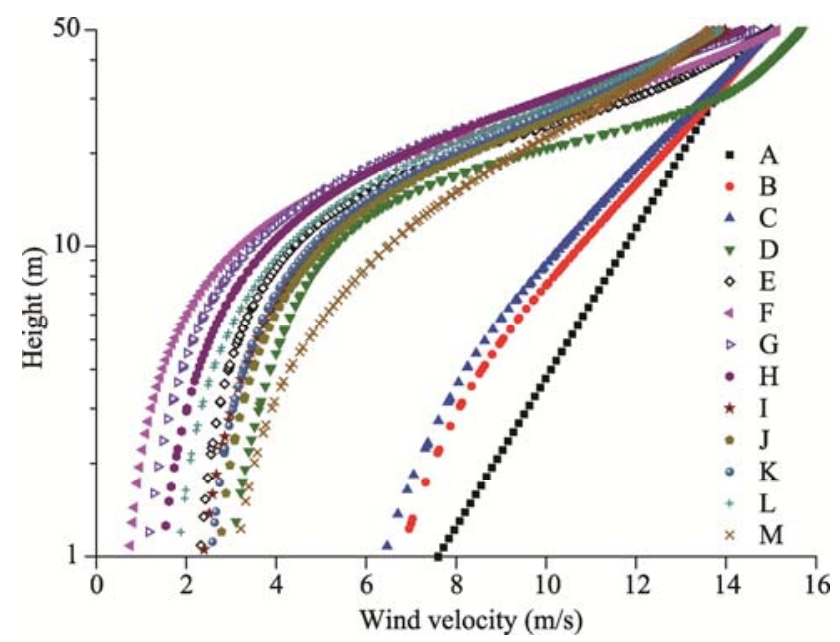

Fig. 5 Simulated wind velocity profiles at locations $A-M$ at the heights of $1-49 \mathrm{~m}$ (see Fig. 2 for A-M locations) 


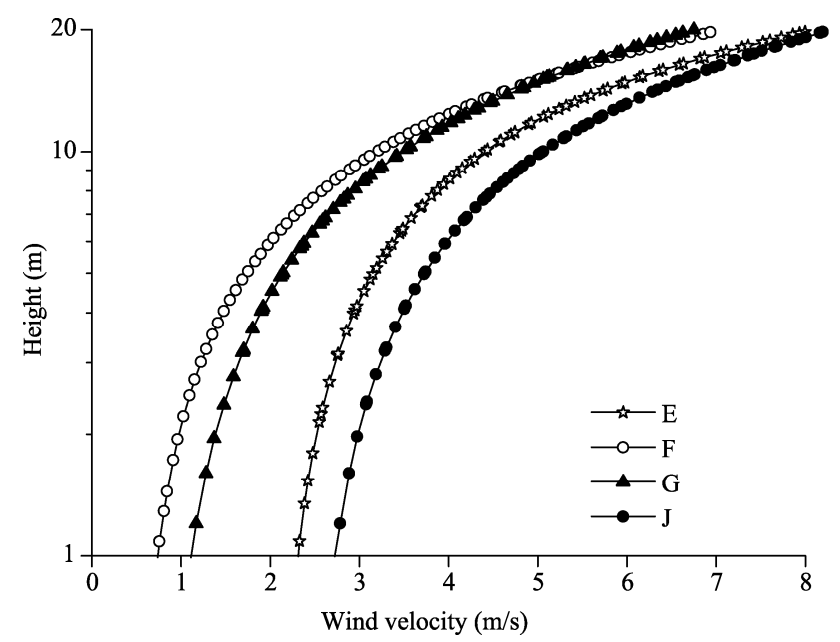

Fig. 6 Simulated wind velocity profiles at locations E, F, G and J below 20-m height (see Fig. 2 for E, F, G and J locations)

\subsection{Horizontal profiles of wind velocity}

To detect the influences of the surface features on wind velocity along a horizontal direction, we plotted the horizontal variations of wind velocity at two heights: 9.0 and $22.5 \mathrm{~m}$. Figure 7 shows that at both the heights, the wind velocity decreased generally with increasing number of sand-fixing forest and windbreak forest arrays with dramatic variations around the windbreak forests, being quite similar to the experimental results by Bradley and Mulhearn (1983) and also by Santiago et al. (2007). It is rather noticeable that those short-spaced windbreak forest arrays (i.e., locations E, F, G and H) are extremely efficient in reducing the wind velocity at the height of $9.0 \mathrm{~m}$. At the height of $22.5 \mathrm{~m}$, those short-spaced windbreak forest arrays (i.e., locations E, F, G and $\mathrm{H}$ ) are still effective in reducing the wind velocity, but the efficiency is considerably lowered in comparison with that at the height of $9.0 \mathrm{~m}$.

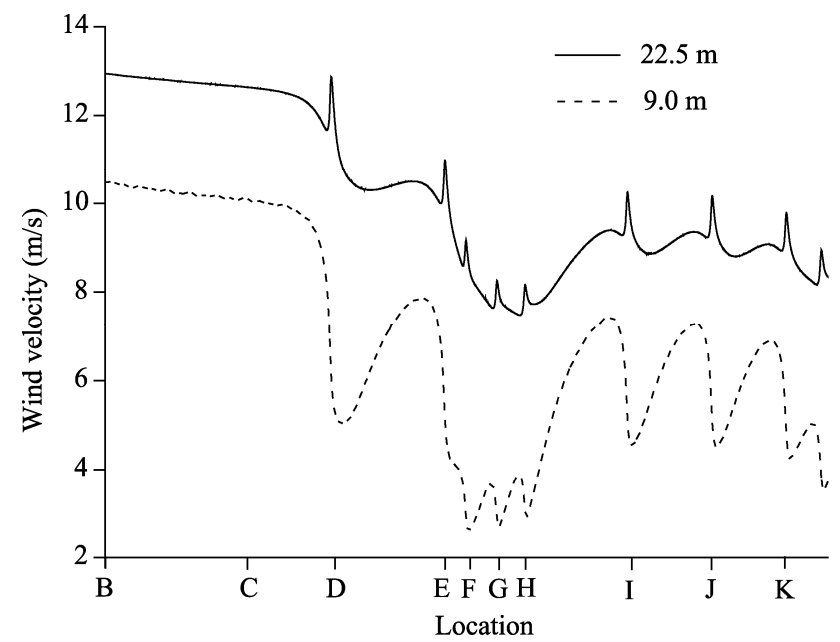

Fig. 7 Horizontal variations of wind velocity at the heights of 9.0 and $22.5 \mathrm{~m}$ from locations B to K (see Fig. 2 for $\mathrm{E}, \mathrm{F}, \mathrm{G}$ and $\mathrm{H}$ locations)

It is notable that the horizontal variations in wind velocity at the height of $9.0 \mathrm{~m}$ are consistent with the experimental results of Nelmes et al. (2001) and Torita and Satou (2007) in showing that the wind velocity decelerates as airflow approaches to the windbreak forests and that the wind velocity accelerates as airflow passes over the windbreak forests. Moreover, our results in the case of $22.5 \mathrm{~m}$ height are consistent with the experimental results of Bradley and Mulhearn 
(1983), i.e., the wind velocity accelerates as airflow approaches to the windbreak forests and then decelerates as airflow passes over the windbreak forests.

\subsection{Influences of sand-fixing and windbreak forests on wind velocity}

To further identify the combined influences of sand-fixing and windbreak forests on wind velocity, we eliminated all sand-fixing forests behind the first array of windbreak forest (location D) in the CFD model and calculated the new wind velocity profiles. Figure 8 shows the wind velocity profiles with the sand-fixing forests and without the sand-fixing forests accompanying the windbreak forests, and Figure 9 shows the discrepancy of wind velocity at the height of $1.0 \mathrm{~m}$ from locations D to L.
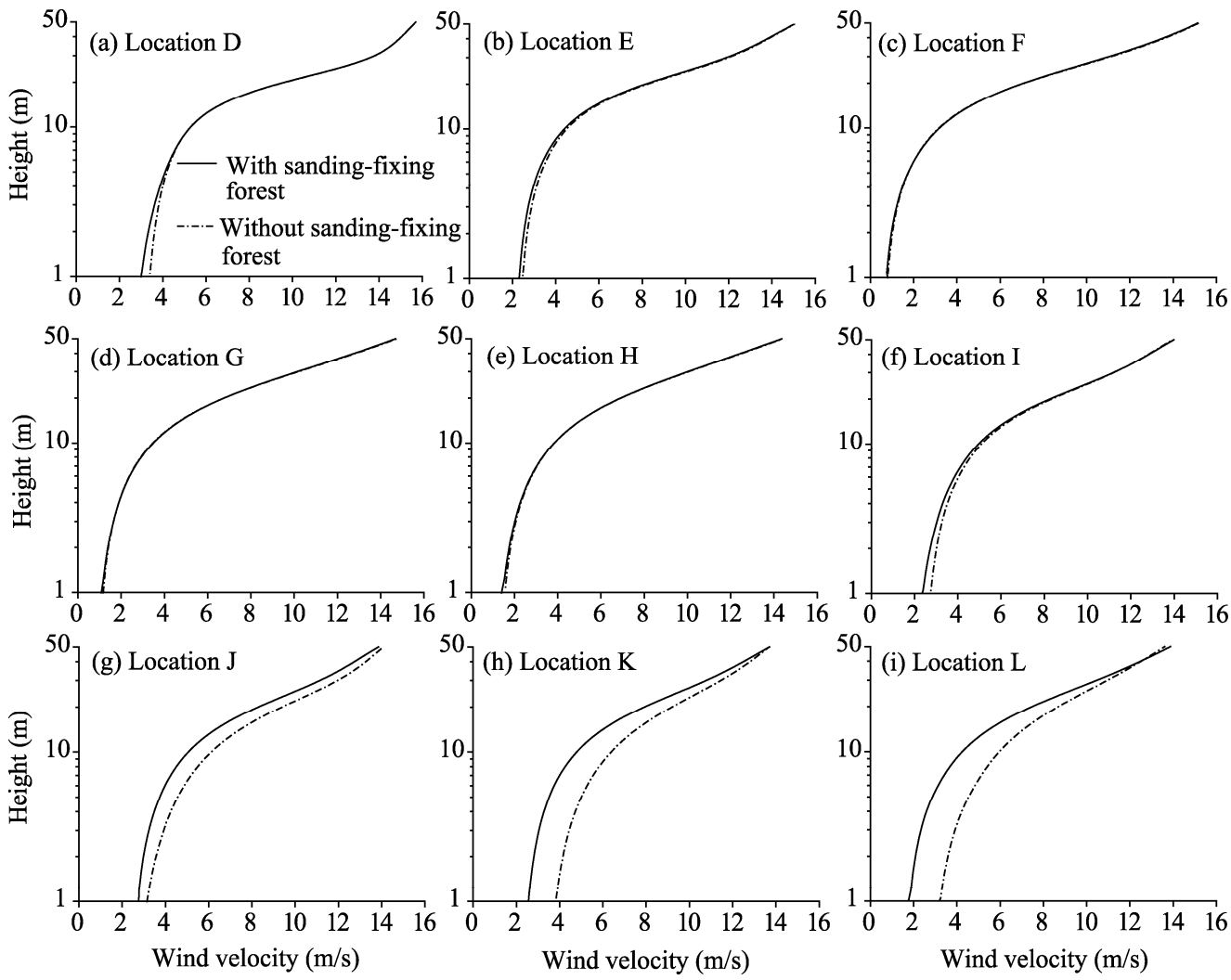

Fig. 8 Simulated wind velocity profiles with and without the sand-fixing forests within the windbreak forests from locations D to $\mathrm{L}$ at the heights of $1-49 \mathrm{~m}$ (see Fig. 2 for locations D-L)

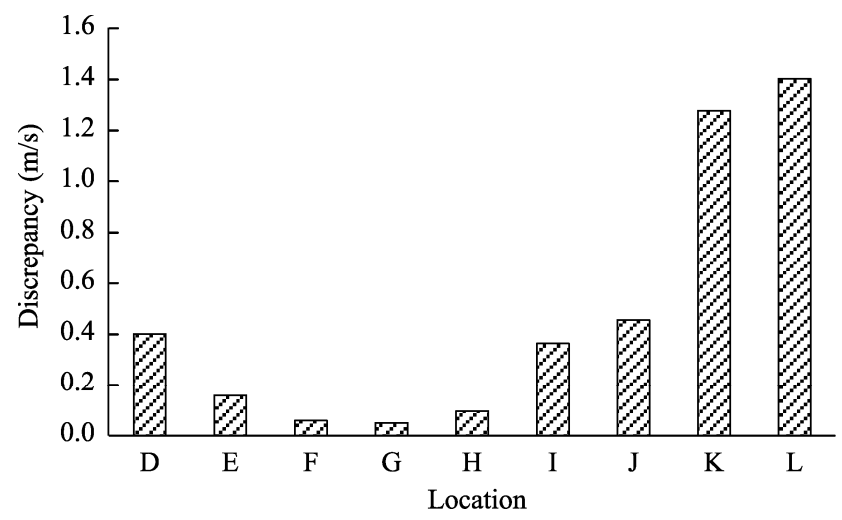

Fig. 9 Wind velocity discrepancy between with and without the sand-fixing forests within the windbreak forests at the height of $1.0 \mathrm{~m}$ from location D to location L (see Fig. 2 for locations of D-L) 
It is obvious that the sand-fixing forests existed within the windbreak forests plays a detectable role in reducing wind velocity and also in reinforcing the sheltering effect of shelterbelt system. However, the efficiency in reducing wind velocity and thus the efficiency in wind-protection effects varied with the array spacings of windbreak forests where the sand-fixing forests existed. For example, from locations $D$ to $G$, the discrepancy in wind velocity at the height of $1.0 \mathrm{~m}$ decreased with increasing array spacings of windbreak forests. And, from locations $G$ to $L$, the discrepancy in wind velocity at the height of $1.0 \mathrm{~m}$ increased with increasing array spacings of windbreak forests (see Fig. 9). These results demonstrate that the wind protection effects of the sand-fixing forests within the entire forest protection system are the most efficient when the arrays of the windbreak forests are adequately spaced (i.e., from location I to location L). However, if the array spacing of windbreak forests is smaller than seven times of the height of windbreak forests (i.e., from location $E$ to location $H$ ), the effects of sand-fixing forests in reducing wind velocity will be diminished or completely masked by the effects of windbreak forests.

Our simulated results confirmed the finding of Judd et al. (1996) and the finding was that the array spacing is a controlling physical parameter for the wind flows in a windbreak system. It means that the numerical simulation base on the experimental parameters is an effective method for studying the interactions of wind flow with array spacing of windbreak forests and thus a useful tool to develop strategies in arranging the patterns of sand-fixing and windbreak forests for preventing wind erosion in the most convenient and the cheapest ways.

\section{Conclusions}

In this study, the wind velocity over the underlying surface with sand-fixing and windbreak forests at the heights of 1-49 m was observed from two 50-m high observation towers within Minqin Oasis. The wind velocities were simulated at different locations over these protective forests between those two towers by a CFD model. Following conclusions can be drawn. First, wind velocity at the heights of 1-49 m showed a logarithmically linear relationship with the height at the edge of the oasis and exhibited a multilayer structure inside the oasis. Second, with increasing number of sand-fixing forest and windbreak forest arrays, the wind velocity at the heights of 1-49 m generally decreased. Third, both the number and array spacing of sand-fixing and windbreak forests can influence the wind velocity. Fourth, the wind protection effects of sand-fixing forests within the windbreak forests were closely related to the array spacing of windbreak forests. The effects increased with the addition of sand-fixing forests when the array of windbreak forests was adequately spaced. However, if the array spacing was smaller than seven times of the heights of the windbreak forests, the effects were reduced or completely masked by the effects of windbreak forests.

\section{Acknowledgements}

This work was supported by the Forestry Industry Research Special Funds for Public Welfare Projects (201404306), the National Natural Science Foundation of China (41371034, 41361001, 31560235), the National Key Technologies R \& D Program of China (2013BAC07B01) and the Gansu Science Foundation for Distinguished Young Scholars (145RJDA327). The authors would like to give special thanks to the editors who contributed greatly to improving the English of this paper.

\section{References}

Alinot C, Masson C. 2005. $K-\varepsilon$ model for the atmospheric boundary layer under various thermal stratifications. Journal of Solar Energy Engineering, 127(4): 438-443.

Amichev B Y, Bentham M J, Cerkowniak D, et al. 2015. Mapping and quantification of planted tree and shrub shelterbelts in Saskatchewan, Canada. Agroforestry Systems, 89(1): 49-65.

Beaucage P, Brower M, Tensen J. 2014. Evaluation of four numerical wind flow models for wind resource mapping. Wind Energy, 17(2): 197-208. 
Blocken B, Stathopoulos T, Carmeliet J. 2007. CFD simulation of the atmospheric boundary layer: wall function problems. Atmospheric Environment, 41(2): 238-252.

Bradley E F, Mulhearn P J. 1983. Development of velocity and shear stress distribution in the wake of a porous shelter fence. Journal of Wind Engineering and Industrial Aerodynamics, 15(1-3): 145-156.

Brandle J R, Hodges L, Zhou X H. 2004. Windbreaks in North American agricultural systems. Agroforestry Systems, 61-62: 65-78.

Chan T L, Dong G, Leung C W, et al. 2002. Validation of a two-dimensional pollutant dispersion model in an isolated street canyon. Atmospheric Environment, 36(5): 861-872.

Cleugh H A. 1998. Effects of windbreaks on airflow, microclimates and crop yields. Agroforestry Systems, 41(1): 55-84.

Cleugh H A, Hughes D E. 2002. Impact of shelter on crop microclimates: a synthesis of results from wind tunnel and field experiments. Australian Journal of Experimental Agriculture, 42(6): 679-701.

Dalpé B, Masson C. 2009. Numerical simulation of wind flow near a forest edge. Journal of Wind Engineering and Industrial Aerodynamics, 97(5-6): 228-241.

Fluent. 1996. FlowLab 1.2 User's Guide. Lebanon: Centerra Resource Park, 7-148.

Guo L J, Li H Q, Sun H Q. 2014. The strategic research on green space system planning of small towns in cold region. Applied Mechanics and Materials, 641-642: 502-505.

Hoffmana C A, Linn R, Parsons R, et al. Modeling spatial and temporal dynamics of wind flow and potential fire behavior following a mountain pine beetle outbreak in a lodgepole pine forest. Agricultural and Forest Meteorology, 204: 79-93.

Huang C H, Lee C I, Tsai C J. 2005. Reduction of particle reentrainment using porous fence in front of dust samples. Journal of Environmental Engineering, 131(12): 1644-1648.

Judd M J, Raupach M R, Finnigan J J. 1996. A wind tunnel study of turbulent flow around single and multiple windbreaks, part I: velocity fields. Boundary-Layer Meteorology, 80(1-2): 127-165.

Katul G G, Mahrt L, Poggi D, et al. 2004. ONE-and TWO-equation models for canopy turbulence. Boundary-Layer Meteorology, 113(1): 81-109.

Kobayashi M H, Pereira J C F, Siqueira M B B. 1994. Numerical study of the turbulent flow over and in a model forest on a 2D hill. Journal of Wind Engineering and Industrial Aerodynamics, 53(3): 357-374.

Lecrivain G, Slaouti A, Payton C, et al. 2008. Using reverse engineering and computational fluid dynamics to investigate a lower arm amputee swimmer's performance. Journal of Biomechanics, 41(13): 2855-2859.

Lee S J, Lim H C. 2001. A numerical study on flow around a triangular prism located behind a porous fence. Fluid Dynamics Research, 28(3): 209-221.

Lee S J, Park K C, Park C W. 2002. Wind tunnel observations about the shelter effect of porous fences on the sand particle movements. Atmospheric Environment, 36(9): 1453-1463.

Li F R, Liu J L, Sun T S, et al. 2016. Impact of established shrub shelterbelts around oases on the diversity of ground beetles in arid ecosystems of northwestern China. Insect Conservation \& Diversity, 9(2): 135-148.

Li L, Li X F, Lin B R, et al. 2006. Improved $k-\varepsilon$ two-equation turbulence model for canopy flow. Atmospheric Environment, 40(4): 762-770.

Li W, Wang F, Bell S. 2007. Simulating the sheltering effects of windbreaks in urban outdoor open space. Journal of Wind Engineering and Industrial Aerodynamics, 95(7): 533-549.

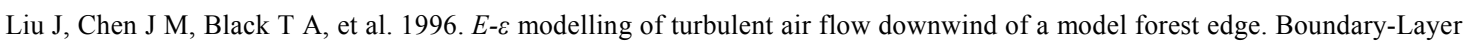
Meteorology, 77(1): 21-44.

Mohammed A E, Stigter C J, Adam H S. 1996. On shelterbelt design for combating sand invasion. Agriculture, Ecosystems \& Environment, 57(2-3): 81-90.

Nelmes S, Belcher R E, Wood C J. 2001. A method for routine characterisation of shelterbelts. Agricultural and Forest Meteorology, 106(4): 303-315.

Patton E G, Shaw R H, Judd M J, et al. 1998. Large-eddy simulation of windbreak flow. Boundary-Layer Meteorology, 87(2): 275-307.

Santiago J L, Martín F, Cuerva A, et al. 2007. Experimental and numerical study of wind flow behind windbreaks. Atmospheric Environment, 41(30): 6406-6420.

Sanz C. 2003. A note on $k-\varepsilon$ modelling of vegetation canopy air-flows. Boundary-Layer Meteorology, 108(1): $191-197$.

Schwartz R C, Fryrear D W, Harris B L, et al. 1995. Mean flow and shear stress distributions as influenced by vegetative windbreak structure. Agricultural and Forest Meteorology, 75(1-3): 1-22.

Shih T H, Liou W W, Shabbir A, et al. 1995. A new $k$ - $\epsilon$ eddy viscosity model for high reynolds number turbulent flows. Computers \& Fluids, 24(3): 227-238. 
Takahashi S, Du M Y, Wu P M, et al. 1998. Three dimensional numerical simulation of the flow over complex terrain with windbreak hedge. Environmental Modelling \& Software, 13(3-4): 257-265.

Torita H, Satou H. 2007. Relationship between shelterbelt structure and mean wind reduction. Agricultural and Forest Meteorology, 145(3-4): 186-194.

Tuzet A, Wilson J D. 2007. Measured winds about a thick hedge. Agricultural and Forest Meteorology, 145(3-4): $195-205$.

Ucar T, Hall F R. 2001. Windbreaks as a pesticide drift mitigation strategy: a review. Pest Management Science, 57(8): 663-675.

Wang H, Takle E S. 1995. A numerical simulation of boundary-layer flows near shelterbelts. Boundary-Layer Meteorology, 75(1-2): 141-173.

Wang H J, Zhou H. 2003. A simulation study on the eco-environmental effects of $3 \mathrm{~N}$ Shelterbelt in North China. Global and Planetary Change, 37(3-4): 231-246.

Wilson J D. 1985. Numerical studies of flow through a windbreak. Journal of Wind Engineering and Industrial Aerodynamics, 21(2): 119-154.

Wilson J D. 2004. Oblique, stratified winds about a shelter fence. Part I: Measurements. Journal of Applied Meteorology, 43(8): $1149-1167$.

Wolfe S A, Nickling W G. 1993. The protective role of sparse vegetation in wind erosion. Progress in Physical Geography, 17(1): 50-68.

Zhu T Y, Zhou G S. 1993. Reduction pattern of wind-speed in farmland windbreak network region. Chinese Journal of Applied Ecology, 4(2): 136-140. (in Chinese) 